\title{
Projecting Chromatic Aberrations
}

David L. Gibbs Jr.

Univeristy of North Florida

Phil Ryan

Univeristy of North Florida

Jay S. Huebner

University of North Florida, jhuebn@unf.edu

Follow this and additional works at: https://digitalcommons.unf.edu/ojii_volumes

Part of the Physical Sciences and Mathematics Commons

\section{Suggested Citation}

Gibbs, David L. Jr.; Ryan, Phil; and Huebner, Jay S., "Projecting Chromatic Aberrations" (2001). All Volumes (2001-2008). 123.

https://digitalcommons.unf.edu/ojii_volumes/123

This Article is brought to you for free and open access by the The Osprey Journal of Ideas and Inquiry at UNF Digital Commons. It has been accepted for inclusion in All Volumes (2001-2008) by an authorized administrator of UNF Digital Commons. For more information, please contact Digital Projects.

(C) 2001 All Rights Reserved

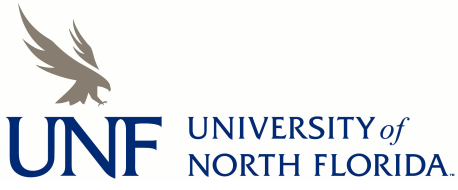




\section{Projecting Chromatic}

Aberrations

(In press, American Journal of Physics)

David L. Gibbs, Jr. and Phil Ryan

Faculty Sponsor: Dr. Jay S. Huebner,
Professor of Physics

The chromatic aberration of lenses is a popular topic in introductory astronomy ${ }^{1-4}$ and physics ${ }^{5-8}$ and is readily demonstrated on an optical bench to several students at a time. ${ }^{9,10}$ However, we are not aware of any published descriptions of demonstrations showing chromatic aberration that are useful for large lecture classes. This note describes a simple method of using an overhead projector and an extra lens for displaying chromatic aberrations in large lecture halls so it can be viewed by large audiences.

Standard overhead projectors ${ }^{11,12}$ have two converging lenses. The first is a large plastic Fresnel lens just under the transparent (typically glass) object table on which the transparency is usually placed. This lens directs light to a second and moveable lens that focuses the transparency image on a (typically) wall-mounted screen. The second lens is a composite of two converging lenses and a front-surface mirror. All that is needed for projecting a large image showing chromatic aberrations is an overhead projector and a large third converging lens that exhibits chromatic aberration.

With the projector at the usual distance from a screen, inserting the third lens into the light path between the projector and screen will project chromatic aberrations on the screen. It is convenient to use a large Fresnel lens similar to the first lens for the third lens, although large glass lenses exhibit the phenomena equally as well. However, the greater weight of a large glass lens is a significant disadvantage. Lenses of focal length from 10 to $50 \mathrm{~cm}$ perform well. With longer focal lengths the lens diameter needs to be larger in order to intercept the entire projected light beam. With the third lens centered in the light beam between the second lens and the screen and within its focal length of the second lens, a large spot will be projected on the screen that is white in the center with a bright red-orange halo. The total image typically fills around $60 \%$ of the area normally occupied by the transparency images.

Moving the third lens readily modifies this image. As the third lens is moved away from the projector and toward the screen, the red-orange halo disappears as an image of the projector bulb appears. For BVE bulbs, 11 this image shows the multiple coils of the bulb's incandescent filament. With ENX bulbs, ${ }^{12}$ a circular and colorful-flower like pattern appears, showing the filament reflected in the bulb's multiple mirrorreflector segments.

Moving the third lens further (two or three times its focal length) from the projector once again creates a large white central spot, but this time the spot exhibits a blue halo. All of these images can be seen as well as normal transparency images are seen, and therefore will show chromatic aberration clearly to a large lecture class.

The explanation for color separation is straightforward for teachers, and can be made easier for introductory level students to grasp through the use of color filters ${ }^{13}$ large enough to intercept all of the projected light. Alternately inserting blue and red filters, with the third lens within its focal length of the second lens, shows that blue light is focused to a smaller spot on the screen than is red, illustrating that it is the larger red spot that produces the red-orange halo. A diagram showing red and blue rays in this arrangement, with a simple second lens instead of the mirror and composite (second) lens, is shown in Figure 1A.

With the third lens further from the projector a blue halo can be seen. This halo is produced as the blue light forms a large blue spot and the red light makes a smaller spot. Fig. 1B shows a ray diagram for this arrangement. 
The diagrams in Figurel were generated by the program RAYS, created with Layhey Fortran $90^{14}$ by Phil Ryan in Dr. James L. Garner's PHY 3424 optics class at the University of North Florida. RAYS models non-paraxial rays and spherical thick lenses by calculating the angle of refraction for each ray at each optical interface, ignoring (as used here) reflected rays. The third lens was made identical to the first. The radii of curvature and indexes of refraction ( 1.475 for red and 1.525 for blue) were chosen to give the correct relative focal lengths for lenses as on the referenced overhead projectors, though these values show larger dispersion than normal optical materials. ${ }^{15}$ The horizontal and vertical scales were adjusted to clearly show the different paths of red and blue light rays in small diagrams.

In the latter arrangement (i.e. with the blue edge), the red is focused to a spot further from the projector. One can massacre the English language in class by musing about what might be seen further out from where red light focuses. If there might be any radiation which could be focused "in the fur-red" region, what should it be called? Students will soon suggest infrared, which provides a nice lead-in to the story to how the astronomer Sir William Herschel discovered IR using a thermometer in 1800. ${ }^{16}$

The presence of IR radiation can be conveniently demonstrated by using filters that block all visible light but still transmit IR. Blue, red, and green Lee filters ${ }^{13}$ that are cut to the size of the overhead projector's object table work nicely for this. By stacking these three filters on the object table, all visible light from the projector is blocked. By moving a large IR detector card near the screen, one can quickly locate the area of the projected IR beam. These IR cards ${ }^{17}$ glow sufficiently in the overhead projector's IR. In fact, their glow is easily seen from the back of large lecture halls if the room lights are dimmed.

Chromatic aberration is conveniently demonstrated in small classrooms using the chromatic aberration from the overhead

projector's first lens by simply holding a screen made of typing or tracing paper in the light before it reaches the second lens. A red-orange edge will be seen on the light pattern there. If the paper screen is placed somewhat beyond the second lens, a blue edge will be seen. These chromatic aberrations are also shown in the ray diagrams of Figure 1.

Some overhead projectors ${ }^{12}$ allow the arm holding the second lens to be folded down. If this is done, a blue edge can also be seen above where the second lens normally is. This arrangement can also be used to demonstrate the purpose of the first lens in normal projector usage. By moving the paper screen from the object table upwards through the space where the second lens would be, it is seen that nearly all of the light passing through the object table is directed to the second lens where it can be re-directed to and focused on the screen.

It is also relatively easy to find places where a converging lens can be used to redirect light at the edge of the projector's beam going to the screen (from the second projector lens) to form a new image to the side of the area of the normally projected image. If this lens also exhibits chromatic aberration, the new image can be arranged to have red on one edge, white in the middle, and blue on the other edge, creating a patriotic display for the countries in which red, white, and blue are national colors.

Figure 1. Ray diagrams illustrating the paths of red rays (thin lines) and blue rays (thick lines) passing from the overhead projector bulb on the left through the three lenses described above. In the figure on the left (A), a red halo is projected to the screen (not shown). In the right-hand figure (B), a blue halo is projected. The second lens in overhead projectors is normally a composite of two converging lenses and a mirror, which was replaced here with a simple converging lens of the same equivalent focal length.

$\mathbf{A}$

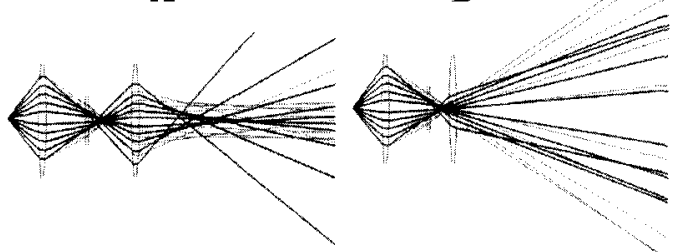




\section{References}

a).Electronic mail jhuebn@unf.edu.

${ }^{1}$ E. Chaisson and S. McMillan, Astronomy Today (Prentice Hall, Upper Saddle River, NJ, 1996) $2^{\text {nd }}$ ed., pages $97-$ 98.

${ }^{2}$ S. Engelbrektson, Astronomy through Space and Time (Wm. C. Brown Pub., Dubuque, IO, 1994) page 79.

${ }^{3}$ P. Flower, Understanding the Universe (West Pub. Co., St. Paul, MN, 1990) page M2-8.

${ }^{4}$ M. A. Seeds, Foundations of Astronomy (Wadsworth Pub. Co., Belmont, CA., 1997) $4^{\text {th }}$ ed., pages $102-4$.

${ }^{5}$ D. Holiday and R. Resnick, Fundamentals of Physics (John Wiley and Sons, New York, 1988) $3^{\text {rd }}$ ed., page 882.

${ }^{6}$ F. W. Sears, M. W. Zemansky and H. D. Young, University Physics (AddisonWesley Pub. Co., 1987) $7^{\text {th }}$ ed., page 896.

${ }^{7}$ J. D. Wilson and A. J. Buffa, College Physics (Prentice Hall, Upper Saddle River, NJ., 1997) $3^{\text {rd }}$ ed., pages $722-23$.

${ }^{8}$ M. E. Rudd, "The rainbow and the achromatic telescope: two case studies," Phys. Teach. 26, 82-89 (1988).

${ }^{9}$ J. S. Huebner and N. Sundarlingam, "Remote controls for infrared experiments," Am. J. Phys. 66, 544-547 (1998).

${ }^{10}$ J. S. Huebner, T. L. Smith and M. D. Reynolds, Basic Astronomy Labs (PrenticeHall, Upper Saddle River, NJ, 1996) pp 8-1 through 8-8.
${ }^{11}$ Model 567 overhead projector, Minnesota Mining and Manufacturing Company, P. O. Box 33224, St. Paul, MN 55133-3224. This model uses a BVE bulb, 625 W, GTE Products Corp., Winchester, KY 40391.

${ }^{12}$ Model 9100 overhead projector, Minnesota Mining and Manufacturing Company, P. O. Box 33224, St. Paul, MN 55133-3224. This model uses an ENX 93525 bulb, $360 \mathrm{~W}$, Osram Corp., $435 \mathrm{E}$. Washington Street, Winchester, KY 40391.

${ }^{13}$ Lee filters, obtained from Jacksonville Stage Lighting, 640 N. Lane Ave., Jacksonville, FL 32254, in $\sim 60$ by 60 $\mathrm{cm}$ sheets for $\sim \$ 6$ each. Cat. Numbers 106, Primary red, 119, Dark blue, and 139, Primary green.

${ }^{14}$ Layhey Fortran 90, Lahey Computer Systems, Inc., 865 Tahoe Blvd., Incline Village, NV 89450.

${ }^{15}$ R. C. West and S. M Selby, Handbook of chemistry and Physics (Chemical Rubber Co., Cleveland $\mathrm{OH}$, 1966) $47^{\text {th }}$ ed, pages E148-53.

16 "Infrared radiation," Britannica Online, http://search.eb.com/bol/ topic?eu=108504\&sctn=4\#s_top", and "Infrared astronomy," Britannica Online, "http://search.eb.com/bol/topic?eu= 43355\&sctn=1\#s_top", both accessed Dec. $14,1999$.

${ }^{17}$ Cat. No. 15990 , IR Sensor with a 5 by $5 \mathrm{~cm}$ active area on $\sim 6 \times 12 \mathrm{~cm}$ card, Oriel Instruments, P. O. Box 872, Stratford, CT 06497. 